\title{
Relationship Between Milk Lactoferrin and Etiological Agent in the Mastitic Bovine Mammary Gland
}

\author{
L. Chaneton, ${ }^{* 1}$ L. Tirante, $†$ J. Maito, $†$ J. Chaves, $†$ and L. E. Bussmann* \\ *Instituto de Biología y Medicina Experimental, CONICET, Buenos Aires, Argentina \\ †Lactodiagnóstico Sur, Buenos Aires, Argentina
}

\begin{abstract}
Bovine mastitis is one of the most deleterious diseases for dairy herds and is mainly caused by contagious and environmental bacterial pathogens. Among contagious bacteria, Staphylococcus aureus is the most prevalent, whereas the main environmental mastitis pathogens are Streptococcus uberis and Escherichia coli. Bovine lactoferrin (bLF) is an approximately $80-\mathrm{kDa}$ glycoprotein present in milk that participates in the innate response of the mammary gland against bacterial infection. The objectives of the current study were to analyze potential changes in bLF milk concentration, which would constitute a response of the mammary gland toward mastitis induced by different etiologic agents, and to evaluate a possible relation between this response and pathogen susceptibility to bLF. Microbiology analysis and bLF quantification in milk from different bovine mammary gland quarters were performed. Infected quarters presented greater concentrations of bLF compared with those from microbiologically negative quarters. Analysis of individual pathogen contributions showed that most of this increase was attributable to Strep. uberis intramammary infection. The ability of mammary gland cells to synthesize bLF in response to Strep. uberis challenge was demonstrated by immunodetection of the protein in in vitro infection experiments. Susceptibility of Strep. uberis, E. coli, and Staph. aureus to the antimicrobial activity of bLF was determined by growth inhibition assays conducted with 4 different isolates of each species. Whereas Staph. aureus and E. coli were shown to be susceptible to this protein, Strep. uberis appeared to be resistant to the antimicrobial activity of bLF. Molecular typing of the 4 Strep. uberis isolates used throughout this study showed that this result was representative of the species and not exclusive of a particular strain. Results presented herein suggest that different bacteria species may elicit different mammary gland responses
\end{abstract}

Received September 27, 2007.

Accepted January 21, 2008.

${ }^{1}$ Corresponding author: chaneton@dna.uba.ar mediated by bLF secretion and that Strep. uberis has probably adapted to this immune reaction by developing resistance to bLF inhibitory action.

Key words: lactoferrin, mastitis, Staphylococcus aureus, Streptococcus uberis

\section{INTRODUCTION}

Bovine mastitis is the most prevalent and costly disease that affects dairy herds and its treatment is the major cause of presence of antibiotic residues in milk. Epidemiologic analyses show that mastitis prevalence in Argentina is 58\% (Chaves et al., 2001). The most prevalent agents associated with this infection are Staphylococcus aureus and different Streptococcus strains. Though less frequent, coliform strains have also been isolated from clinically and subclinically infected cows (Acuña et al., 2001; Chaves et al., 2001). The mammary gland is capable of reacting against bacterial invasion through a complex network of specific and nonspecific defense mechanisms (Sordillo and Streicher, 2002; Oviedo-Boyso et al., 2007). Nonspecific mechanisms are characterized by the recognition of structural motives that are common to many pathogenic bacteria such as peptidoglycan, LPS, and lipoteichoic acid. These defense mechanisms are predominant during early stages of infection and consist of anatomical, cellular, and soluble factors that act in a tightly coordinated fashion. Soluble factors involved in innate immunity are mainly peptides and proteins including, among others, lysozyme, lactoperoxidase, and lactoferrin (LF). Lactoferrin is an approximately $80-\mathrm{kDa}$ iron-binding glycoprotein first recognized in milk and then found in other epithelial secretions and barrier body fluids. Mainly recognized as a bacteriostatic and bactericidal protein (properties attributed to its ability to chelate iron or to bind to the bacterial surface), LF also displays antiviral (Ikeda et al., 2000), antifungal (Takakura et al., 2004), antitumoral (Bezault et al., 1994), and immunomodulating (Brock, 1995) functions. Lactoferrin has been found in milk of many different species including cattle, sheep, goat and human. In cattle milk, bovine $\mathrm{LF}$ (bLF) is present in polymorphonuclear lymphocyte secondary granules and is synthesized 
by cells of the glandular epithelium of the mammary gland (Molenaar et al., 1996). It has been shown that bLF concentration increases during mammary involution (Hurley and Rejman, 1993) and infection (Harmon et al., 1976; Kawai et al., 1999; Komine et al., 2005). Accordingly, bLF has been considered as a relevant factor in mammary gland innate defense mechanisms against IMI. It has been demonstrated that clinical IMI causes a significant increase in bLF concentration (Harmon et al., 1976; Kawai et al., 1999). Some reports have also established associations between subclinical mastitis and increased bLF (Hagiwara et al., 2003); however, data regarding this issue is still scarce. Neutrophil concentration in milk increases during mastitis and involution (Harmon and Newbould, 1980), which could in turn explain the increase of bLF under these circumstances. Nevertheless, as mentioned before, it has been demonstrated that bLF secretion by mammary gland epithelial cells is stimulated during involution (Hurley and Rejman, 1993) and that intramammary bacterial infection is capable of inducing $\mathrm{LF}$ gene transcription in an in vitro model (Wellnitz and Kerr, 2004). Moreover, Harmon and Newbould (1980) have provided evidence that suggests that most of the bLF increase occurring upon mammary gland infection is due to enhanced secretion of mammary gland epithelial cells.

Different mastitis causing agents display distinct invasion and pathogenic mechanisms and therefore are likely to produce dissimilar immune reactions. In fact, different immune responses have been associated with udder infected with Staph. aureus, Strep. uberis, or coliform strains (Hagiwara et al., 2003; Bannerman et al., 2004; Wellnitz and Kerr, 2004). Nevertheless, a clear relation between bLF response and distinct pathogenic agents has not been yet well established. Moreover, it has been reported that susceptibility to bLF is highly variable among bacterial species and strains (Lee et al., 2004). These observations have prompted us to hypothesize that bacteria whose pathogenic strategies induce a greater increment in milk bLF concentration should be more adapted to that environment and in consequence more resistant to this protein than microorganisms that do not cause such an increase. Therefore, the goal of this study was to analyze the potential relationship between mammary gland-infecting bacteria and bLF concentration, and to evaluate the susceptibility of these bacteria to this protein. Because of the multifactorial nature of IMI etiology, the study of mammary gland-pathogen interactions appears to be a fundamental issue to understand the pathophysiology of mastitis and to design adequate diagnosis, treatment, and control policies.

\section{MATERIALS AND METHODS}

\section{Sample Collection and Pathogen Identification}

Milk samples obtained from 305 individual bovine udder quarters from 5 different dairy farms of Argentina were used in this study. Samples were taken irrespective of cow's age, lactation number, or stage of lactation. Foremilk was aseptically collected and maintained at $4{ }^{\circ} \mathrm{C}$ until cultured. When samples could not be processed within $24 \mathrm{~h}$ postcollection, they were frozen at $-18^{\circ} \mathrm{C}$. Samples were cultured by plating $0.05 \mathrm{~mL}$ of milk on blood-esculin agar plates and incubating for 24 to $48 \mathrm{~h}$ at $37^{\circ} \mathrm{C}$. Simultaneously, an aliquot of the sample was incubated for $4 \mathrm{~h}$ at $37^{\circ} \mathrm{C}$ and subsequently plated on blood-esculin agar to recover pathogens present at a low concentration (Dinsmore et al., 1992). Isolation and identification of bacterial species were performed according to recommendations of the National Mastitis Council (Hogan et al., 1999). Clinical mastitic quarters were defined as those that presented evident symptoms of infection (swelling, redness, pain in udder, or clots in milk). A subclinically infected quarter was defined as a quarter positive for IMI but that did not present evident local or systemic symptoms of mammary infection. An IMI in a quarter was defined as isolation of 1 or 2 bacterial species from quarter milk sample. Samples that presented 3 or more bacterial species in the plate were considered contaminated and were not used in this study (Hogan et al., 1999).

\section{Bovine LF Purification and Analysis}

Bovine lactoferrin was purified from milk of healthy multiparous cows. Milk was centrifuged at 10,000 $\times g$ for $20 \mathrm{~min}$ at $4^{\circ} \mathrm{C}$ for delipidation. Skimmed milk was adjusted to $\mathrm{pH} 4.5$ by the addition of $10 \mathrm{~N} \mathrm{HCl}$, the solution was stirred for $30 \mathrm{~min}$ to complete precipitation, and subsequently centrifuged at $15,000 \times g$ at $4^{\circ} \mathrm{C}$ for $30 \mathrm{~min}$ for casein removal. The obtained whey was neutralized by addition of $10 \mathrm{~N} \mathrm{NaOH}$, centrifuged again at $17,700 \times g$ at $4^{\circ} \mathrm{C}$ for $30 \mathrm{~min}$, and then passed through a $0.45-\mu \mathrm{m}$ pore size filter. The filtered whey was loaded into SP-Sepharose Fast Flow cationic-exchange column (GE Healthcare, Piscataway, NY) and after an extensive washing with $0.3 \mathrm{M} \mathrm{NaCl}$ in phosphate buffer ( $\mathrm{pH} 7.0$ ), bLF was eluted with $0.5 M \mathrm{NaCl}$ in phosphate buffer (pH 7.0). Purity of bLF was assessed by $\mathrm{AgNO}_{3}$-stained SDS-PAGE (Shevchenko et al., 1996), where a single $82.9-\mathrm{kDa}$ band was observed. The migration pattern in SDS-PAGE of bLF purified in our lab resulted identical to the one observed with commercial bLF (Sigma Chemical Co., St. Louis, MO). The iron content of bLF was determined as described (Fish, 1988) with minor modifications. Briefly, $0.5 \mathrm{~mL}$ of iron-releasing reagent $(0.6 \mathrm{~N}$ $\mathrm{HCl}, 142 \mathrm{mM} \mathrm{KMnO}$ ) was added to $1 \mathrm{~mL}$ of a $10 \mathrm{mg} /$ $\mathrm{mL}$ bLF solution and incubated for $2 \mathrm{~h}$ at $60^{\circ} \mathrm{C}$. Then, $0.1 \mathrm{~mL}$ of reducing reagent $(6.5 \mathrm{~m} M$ ferrozine, $13.1 \mathrm{~m} M$ neucoproine, $2 M$ ascorbic acid, $5 M$ ammonium acetate) was added and incubated for $30 \mathrm{~min}$ at room tempera- 
ture to allow the formation of magenta-colored reduced ferrozine. Absorbance of the samples were measured at $562 \mathrm{~nm}$ and compared with a standard curve of serially diluted cytochrome $\mathrm{C}$ stock solution.

\section{Generation of bLF-Specific Antibodies}

Bovine LF purified as described above was used to induce specific bLF antibodies in rabbits. Four animals were injected with $100 \mu \mathrm{g}$ of bLF in complete Freund's adjuvant and boosted on 3 subsequent occasions by injection of $100 \mu \mathrm{g}$ of bLF in incomplete Freund's adjuvant, at 14,28 , and $56 \mathrm{~d}$ after initial inoculation. Hyperimmune serum was recovered $80 \mathrm{~d}$ after antigen injection. Procedures were reviewed and approved by the Animal Research Committee from the Institute of Biology and Experimental Medicine, Argentina, which follows the guidelines of the Animal Welfare Act, USDA (Halliday et al., 2004). Serum from each rabbit was separately collected and bLF antibody titer was determined by immunoprecipitation. Bovine LF-specific antibodies were purified from highest titer antisera using a bLF-Sepharose affinity column. Briefly, $10 \mathrm{mg}$ of bLF in $1 \mathrm{~mL}$ of coupling buffer $\left(200 \mathrm{~m} M \mathrm{NaHCO}_{3}, 500 \mathrm{~m} M \mathrm{NaCl}\right.$, pH 8.3) was added to $1 \mathrm{~mL}$ of Hi-Trap NHS activated column (GE Healthcare) and incubated for $1 \mathrm{~h}$ at room temperature. After deactivation of the remaining active groups, the column was washed with PBS, then with elution buffer (100 $\mathrm{m} M$ glycine, $\mathrm{pH} 2.5)$ and finally equilibrated with PBS-Tween [PBS + 0.05\% (vol/vol) Tween 20]. Half diluted serum in PBS-Tween was loaded into the column and washed with $0.6 M \mathrm{NaCl}$ in $50 \mathrm{~m} M$ phosphate buffer, $\mathrm{pH}$ 7.0. Elution was performed with $100 \mathrm{mM}$ glycine buffer ( $\mathrm{pH} 2.5$ ), and 1-mL fractions were collected into $50 \mu \mathrm{L}$ of $1.5 M$ Tris-HCl ( $\mathrm{pH}$ 8.6). Absorbance was measured at $280 \mathrm{~nm}$, and fractions containing affinity-purified IgG were pooled and used in the immunoassays. Specificity of the resulting antibodies was evaluated by Western blot of bLF and compared with commercial goat anti-bLF antibodies (Bethyl Laboratories Inc., Montgomery, TX). Immunoblots were developed using secondary antibodies conjugated with peroxidase and $\mathrm{H}_{2} \mathrm{O}_{2}$ and diamino benzidine as substrate and $\mathrm{H}^{+}$donor, respectively.

\section{Bovine LF Quantification by Competitive ELISA}

Bovine LF antibodies were used in a bLF-biotin competitive ELISA. Bovine LF purified as described above was biotinylated with NHS-LC-Biotin (Pierce Chemicals Co., Rockford, IL) according to the manufacturer's instructions. High-binding 96-well microtiter plates (Nunc A/S, Roskilde, Denmark) were coated with $100 \mu \mathrm{L} /$ well of bLF-specific antibody solution $(3 \mu \mathrm{g} / \mathrm{mL}$ in $200 \mathrm{mM}$
$\mathrm{NaHCO}_{3}, \mathrm{pH} 8.3$ ) and incubated overnight at $4^{\circ} \mathrm{C}$. Nonspecific binding was blocked by incubating plates with $10 \%$ normal goat serum in TBS-Tween [Tris-buffered saline with $0.05 \%$ (vol/vol) Tween $20, \mathrm{pH} 7.5$ ] for $2 \mathrm{~h}$ at room temperature. Four microliters of whey from milk samples obtained by centrifugation of acidified milk was mixed with TBS-Tween containing $0.15 \mu \mathrm{g}$ of biotin tagged-LF to a final volume of $100 \mu \mathrm{L}$. This mix was placed in duplicate into anti-bLF antibody-coated wells for $60 \mathrm{~min}$ at RT. After incubation, wells were washed and incubated for additional 60 min at RT with ExtraAvidin-alkaline phosphatase (Sigma Chemical Co.) in TBSTween. Wells were washed with high salt TBS-Tween (TBS-Tween $+0.6 \mathrm{M} \mathrm{NaCl}, \mathrm{pH} 7.5$ ) and the color reaction was allowed to develop by addition of $0.5 \%(\mathrm{wt} / \mathrm{vol}) p$ nitrophenyl phosphate in $100 \mathrm{~m} M$ Tris $(\mathrm{pH}$ 9.5) and 5 $\mathrm{mM} \mathrm{MgCl}$. A calibration curve was prepared by serial dilutions of a bLF stock solution of a known concentration mixed with biotin tagged-LF in a similar way as with milk whey samples. Absorbance at $405 \mathrm{~nm}$ was measured in a microplate reader and the standard curve was generated by fitting its values to a 4-parameter logistic equation. Concentrations of bLF in milk whey were determined by interpolating $405 \mathrm{~nm}$ absorbance values of samples into the calibration curve.

\section{In Vitro Infection and Analysis of bLF Expression}

Primary cultures of bovine mammary gland cells were generated as previously reported (Bussmann et al., 2004; Chaneton et al., 2004). Mammary cells were cultured in Dulbecco's modified Eagle medium-F12 with 5\% fetal bovine serum, supplemented with $5 \mu \mathrm{g} / \mathrm{mL}$ of insulin, $1 \mu \mathrm{g} / \mathrm{mL}$ of hydrocortisone, at $37^{\circ} \mathrm{C}$ under humidified conditions and $5 \% \mathrm{CO}_{2}$. For in vitro infection experiments, cells were plated at a density of 125,000 cells/ $\mathrm{cm}^{2}$ and incubated to confluence in a multichamber slide (Lab-Tek Chamber Slide, Nalgene Nunc International Corp., Naperville, IL). Suspensions of Strep. uberis were added at a multiplicity of infection of approximately 1 and incubated for $3 \mathrm{~h}$. Then, cells were washed with PBS containing gentamicin $(100 \mu \mathrm{g} / \mathrm{mL})$ and Dulbecco's modified Eagle medium-F12 medium was added. Immunofluorescence assays were performed as described previously (Bussmann et al., 2006). Briefly, at $24 \mathrm{~h}$ postinfection cells were fixed in $p$-formaldehyde (4\%) for 10 min. After washing with PBS, cells were permeabilized for 30 min in Triton X-100 (0.25\%, Promega, Madison, WI), washed afterwards with PBS and blocked for 30 min with $5 \%$ donkey normal serum in PBS-Tween 20 $(0.05 \%)$. Incubation with first antibody against bLF raised in rabbit diluted 1:500 was done for $60 \mathrm{~min}$ at RT. Thereafter, cells were washed with PBS and incubated with Cy3-conjugated donkey anti-rabbit IgG 


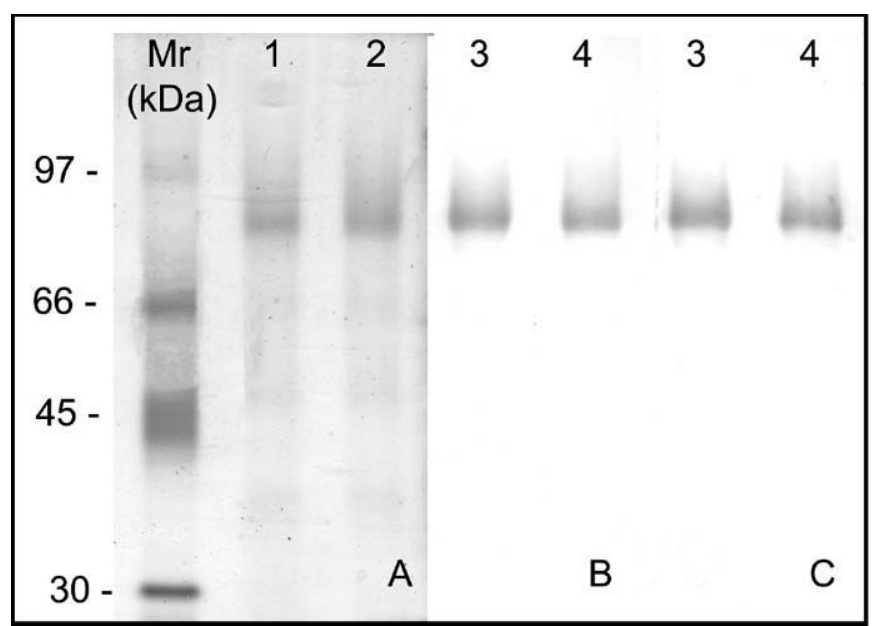

Figure 1. Bovine lactoferrin (bLF) purchased from Sigma (St. Louis, MO) or purified in this study was resolved in 10\% SDS-PAGE. A) silver stain of $0.5 \mu \mathrm{g}$ of bLF of commercial origin (lane 1) or isolated in our laboratory (lane 2). B) Western blot of $0.1 \mu \mathrm{g}$ of commercial bLF (lane 3) or our laboratory isolation of the protein (lane 4), using a commercial anti-bLF antibody. C) Western blot of $0.1 \mu \mathrm{g}$ of commercial bLF (lane 3) or our laboratory isolation of the protein (line 4), using anti-bLF antibody made in our laboratory. $\mathrm{Mr}=$ low-molecularweight standard.

(Jackson ImmunoResearch, West Grove, PA) diluted 1:100 for $1 \mathrm{~h}$ at room temperature. After washing with PBS, samples were allowed to dry and then mounted with Mowiol 4-88 mounting media (EMD Bioscience Inc., La Jolla, CA).

\section{Microbiological Assays}

Four isolations each of Strep. uberis and Staph. aureus from subclinically infected quarters and 4 isolations of $E$. coli from clinically infected quarters were used in this study. Mastitis-causing bacteria were isolated and identified following National Mastitis Council guidelines (Hogan et al., 1999). All bacteria were maintained on peptone yeast extract agar slants at $4^{\circ} \mathrm{C}$ and were subcultured every 2 mo to ensure viability. The working inoculum of bacteria was prepared by subculturing isolates from agar slants into peptone yeast extract broth and incubating for $16 \mathrm{~h}$. After incubation, $0.02 \mathrm{~mL}$ of each culture was inoculated into $2 \mathrm{~mL}$ of fresh peptone yeast extract broth and the mixture was further incubated for $3 \mathrm{~h}$ at $37^{\circ} \mathrm{C}$. The culture was then diluted in saline to $4 \times 10^{4} \mathrm{cfu} / \mathrm{mL}$ and the suspension placed in microtubes as follows. To each microtube was added 12 $\mu \mathrm{L}$ of antibiotic medium $[0.15 \%(\mathrm{wt} / \mathrm{vol})$ meat extract, $0.15 \%(\mathrm{wt} / \mathrm{vol})$ yeast extract, $0.5 \%$ (wt/vol) peptone, $0.1 \%$ (wt/vol) dextrose, $0.35 \%$ (wt/vol) $\mathrm{NaCl}, 0.37 \%$ (wt/vol) $\mathrm{K}_{2} \mathrm{HPO}_{4}, 0.13 \%$ (wt/vol) $\mathrm{KH}_{2} \mathrm{PO}_{4}$; Difco, Detroit, $\mathrm{MI}$, 4 $\mu \mathrm{L}$ of bLF $(10 \mathrm{mg} / \mathrm{mL})$ (final concentration: $2 \mathrm{mg} / \mathrm{mL}$ ) and $4 \mu \mathrm{L}$ of bacterial inoculum (approximately $160 \mathrm{cfu}$ ). Growth controls contained sterile water instead of protein solution. After $6 \mathrm{~h}$ of culture, bacterial counts were assessed in both bLF containing tubes and control tubes.

\section{Molecular Typing of Strep. uberis Strains}

Molecular typing of Strep. uberis strains was performed by random amplification of polymorphic DNA as described previously (Wieliczko et al., 2002). Chromosomal DNA from Strep. uberis was extracted as described (Wieliczko et al., 2002). Oligonucleotide primer Ope-4 (5' GTGACAGCC 3') was synthesized by Invitrogen (Carlsbad, CA). The PCR mix reaction consisted of $10 \mathrm{mM}$ Tris, pH 8.3; $2.5 \mathrm{~m} M \mathrm{MgCl}_{2} ; 50 \mathrm{~m} M \mathrm{KCl} ; 250 \mu M$ each deoxynucleotide triphosphate; $0.56 \mu M$ Ope-4 primer, and $3.0 \mathrm{U}$ of Taq DNA polymerase in a final volume of 50 $\mu \mathrm{L}$. The reaction was run for 45 cycles in a Mastercycler Personal Eppendorf thermocycler (Eppendorf AG, Hamburg, Germany) using the following program: denaturation at $94^{\circ} \mathrm{C}$ for $2 \mathrm{~min}$, annealing at $33^{\circ} \mathrm{C}$ for $30 \mathrm{~s}$, elongation at $72^{\circ} \mathrm{C}$ for $2 \mathrm{~min}$. The PCR products were electrophoresed in $2 \%$ agarose gel and stained with ethidium bromide.

\section{Statistical Analyses}

A 2-tailed Mann-Whitney test (GraphPad Prism version 4.0 for Windows; GraphPad Software Inc., San Diego, CA) was used to compare mean values of bLF concentration in microbiologically negative and positive mammary gland quarters. This method was used for subclinical and clinical mastitis. Discriminative comparison between negative quarters and those positive for different mastitis-causing agents was performed using a 2-tailed Kruskal-Wallis test and a Dunn's multiple comparison test as post-test (GraphPad Prism). For growth inhibition assays, a 2-tailed unpaired $t$-test (GraphPad Prism) was used to compare bacterial counts $(\mathrm{cfu} / \mathrm{mL})$ in bLF-treated and control wells.

\section{RESULTS}

\section{Bovine LF Purification and Analysis}

Bovine LF was purified from normal milk and the purity of the preparation was confirmed in silver-stained SDS-PAGE and Western blot experiments using standard commercial bLF as control (Figure 1). The iron content of purified bLF was analyzed as described in the Materials and Methods section, with a degree of saturation of $30 \%$. 


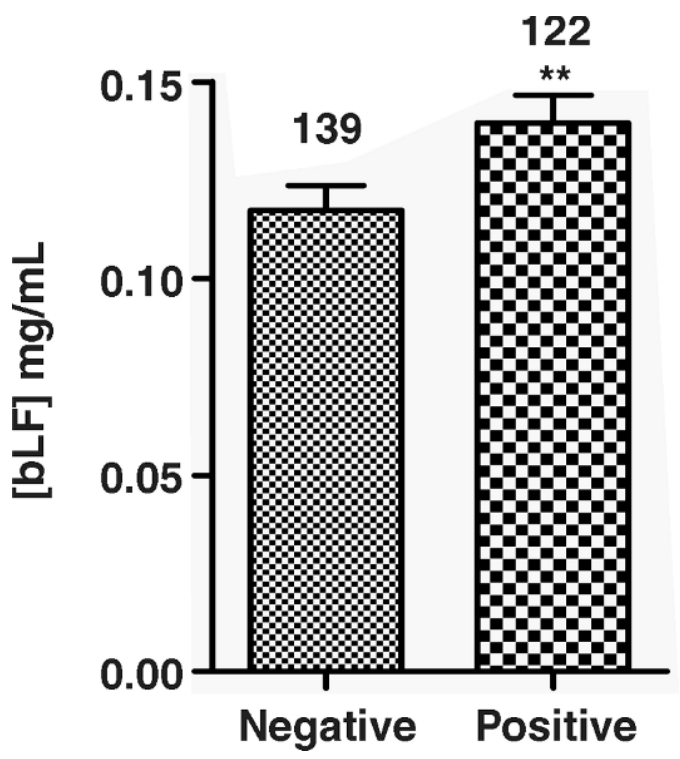

Figure 2. Bovine lactoferrin (bLF) concentration (mean \pm SEM) in milk samples negative or positive for isolation of mastitis-causing bacteria. All samples were obtained from quarters that did not present evident signs of clinical infection. Numbers above columns indicate sample size in each category; ${ }^{* *} P<0.01$.

\section{Bovine LF Content in Subclinically Infected and Noninfected Quarters}

Individual quarters from cows belonging to 5 different Argentinean dairy farms were analyzed in this study. Each sample was assessed for the presence of mastitiscausing bacteria by conventional identification protocols. Bovine LF concentration in milk was evaluated by competitive ELISA using biotin-tagged bLF and antibodies against bLF. Quarters positive for mastitis-causing bacteria showed greater bLF concentrations $(P<0.01)$ than microbiologically negative quarters (Figure 2 ). The association between bLF concentration and IMI suggested a bLF-dependent response of the mammary gland to bacterial infection, even when there was no detectable inflammation process. Microbiologically positive quarters were classified according to the pathogen present in the sample to analyze the contribution of each etiological agent to milk concentration of bLF. Streptococcus uberispositive quarters showed greater bLF concentrations than did negative quarters $(P<0.001)$, whereas other mastitis-causing bacteria, such as Staph. aureus, CNS, and Streptococcus dysgalactiae did not seem to be associated with an increase in bLF concentration (Figure 3). These results suggest a pathogen-specific bLF response to infection.

\section{Bovine LF Content in Clinically Infected Quarters}

Forty-four quarters with clinical mastitis were also analyzed for milk bLF content (Figure 4). Bovine LF

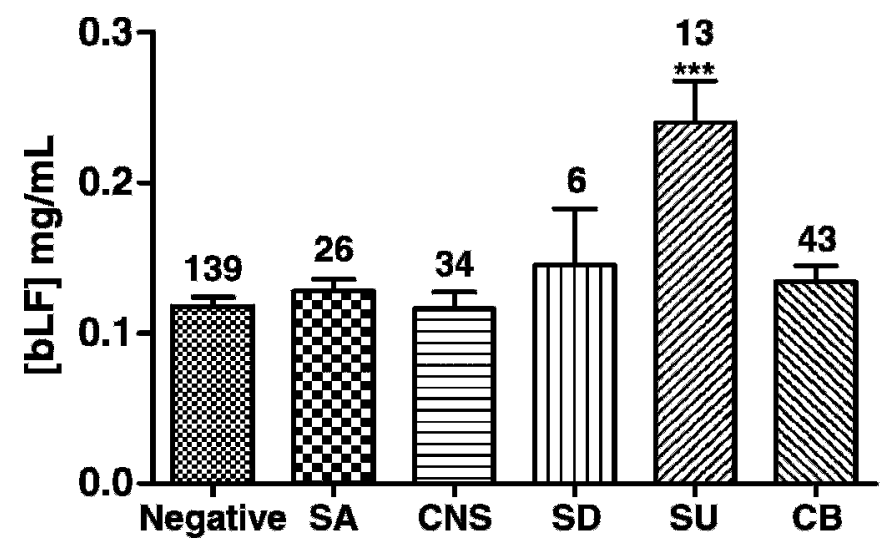

Figure 3. Bovine lactoferrin (bLF) concentration (mean \pm SEM) in milk from microbiologically negative milk samples and samples positive for Staphylococcus aureus (SA), CNS, Streptococcus dysgalactiae (SD), Streptococcus uberis (SU), and Corynebacterium bovis (CB). Samples were obtained from quarters that presented no evident signs of clinical infection. Numbers above columns indicate sample size in each category; $* * * P<0.001$.

concentration was considerably greater in clinically infected quarters when compared with subclinical quarters $(P<0.001)$. No differences in milk bLF content were found among udder quarters infected with different pathogenic agents (Figure 5).

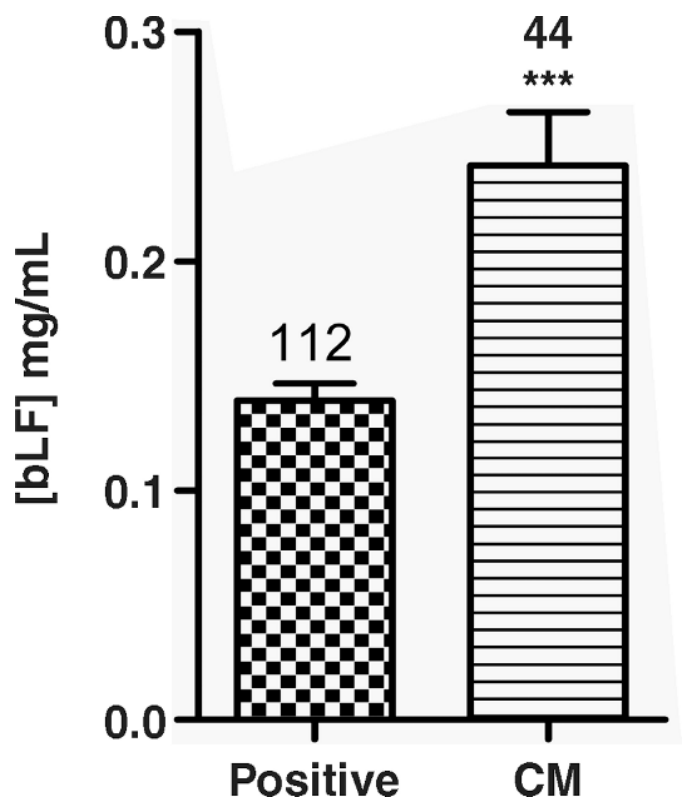

Figure 4. Bovine lactoferrin (bLF) concentration (mean \pm SEM) in milk from quarters positive for isolation of mastitis-causing bacteria but showing no signs of infection and quarters that presented evident symptoms of clinical mastitis (CM). Numbers above columns indicate sample size in each category; ${ }^{* * *} P<0.001$. 


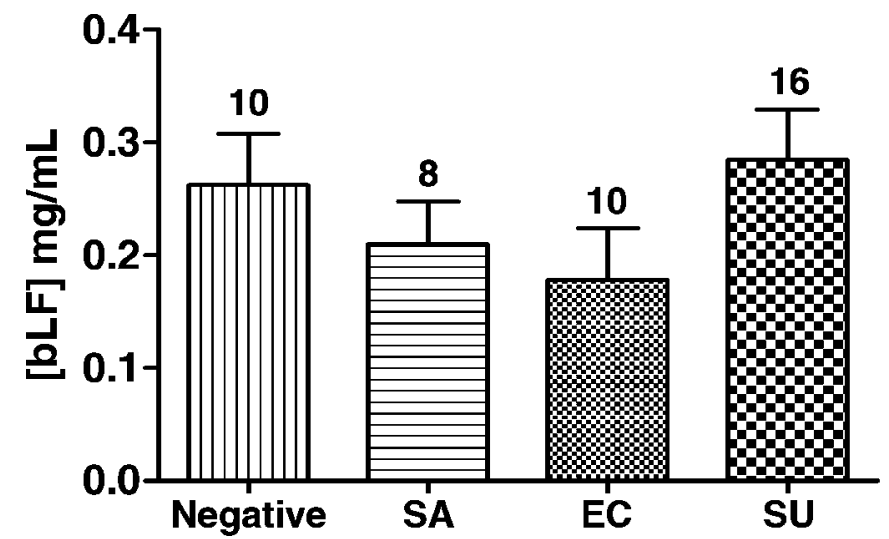

Figure 5. Bovine lactoferrin (bLF) concentration (mean \pm SEM) in milk from clinically infected quarters that were microbiologically negative or positive for Staphylococcus aureus (SA), Streptococcus uberis (SU), and Escherichia coli (EC). Numbers above columns indicate sample size in each category.

\section{Lactoferrin Expression by Bovine Mammary Gland Cells}

We presented evidence that IMI can induce a bLFmediated response in the mammary gland and that this response seems to be different depending on the invading agent. It is not clear, however, whether this response is mediated by mammary epithelial cells or by neutrophils migrating from the bloodstream. One possible approach to address this issue is to determine if epithelial cells of the mammary gland are capable to produce bLF and if so, whether this production increases in response to Strep. uberis infection. Consequently, in vitro infection experiments were performed by challenging a primary culture of bovine mammary cells with a suspension of Strep. uberis isolated from subclinically infected mammary gland. Immunofluorescence analysis showed that mammary gland cells are capable to synthesize bLF and that this production is increased when they are treated with a suspension of Strep. uberis (Figure 6). This result confirms that mammary epithelial cells are capable of producing bLF and that this production is enhanced upon Strep. uberis infection.

\section{Susceptibility of Mastitis-Causing Bacterial Isolations to bLF}

Our results outlined in Figure 2 demonstrate that there are differences in bLF concentration among quarters infected with different pathogen agents. Among the major pathogens, Strep. uberis seems to be associated with greater bLF concentration (Figure 2). Consequently, we decided to investigate a possible relationship between differential mammary gland bLF response to different pathogenic agents and their susceptibility to
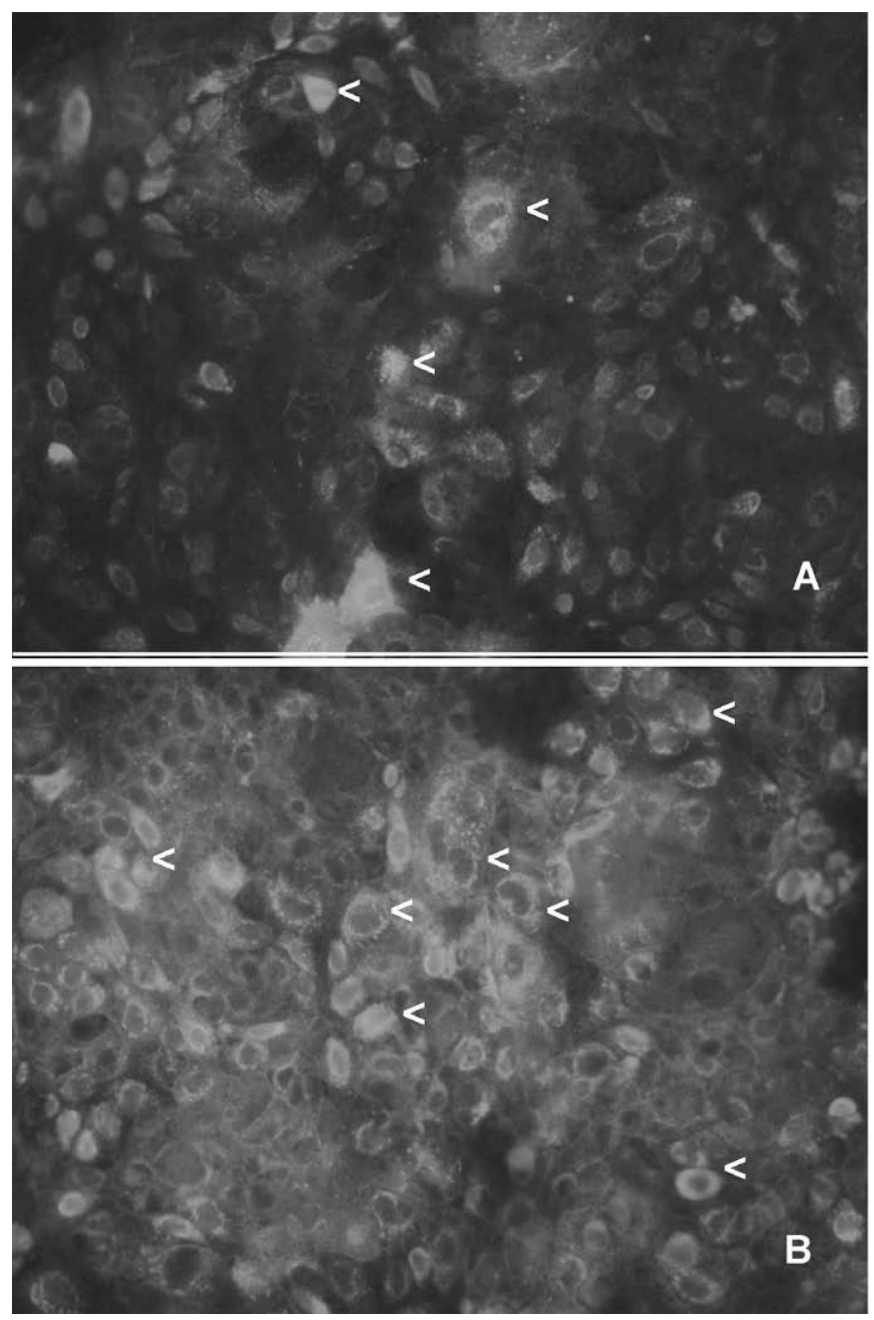

Figure 6. Lactoferrin expression in vivo by primary cultures of bovine mammary cells. A) Immunofluorescence for bovine lactoferrin (bLF) in control (noninfected) mammary cells. B) Immunofluorescence for bLF in mammary cells infected with Streptococcus uberis. Arrowheads indicate representative immunostaining of cytoplasmic bLF. Magnification $=400 \times$. The same pattern of response was obtained in 2 independent experiments each run in duplicate.

this protein. Bacterial growth inhibition assays with 4 isolations of Strep. uberis, E. coli, and Staph. aureus obtained from local dairy herds were performed. The 12 isolations were grown in the presence or absence of 2 $\mathrm{mg} / \mathrm{mL}$ of bLF purified from milk from local dairy cows and growth levels were monitored after $6 \mathrm{~h}$ of culture by measuring either optical density at $600 \mathrm{~nm}$ (data not shown) or bacterial counts (cfu/mL; Figure 7). Escherichia coli and Staph. aureus were inhibited by bLF ( $P$ $<0.001$ ), whereas Strep. uberis growth was not affected by the presence of this protein in the culture medium. Differences in inhibition levels were observed between the 2 susceptible species, with Staph. aureus being more susceptible than $E$. coli (Figure 7). To determine if the 

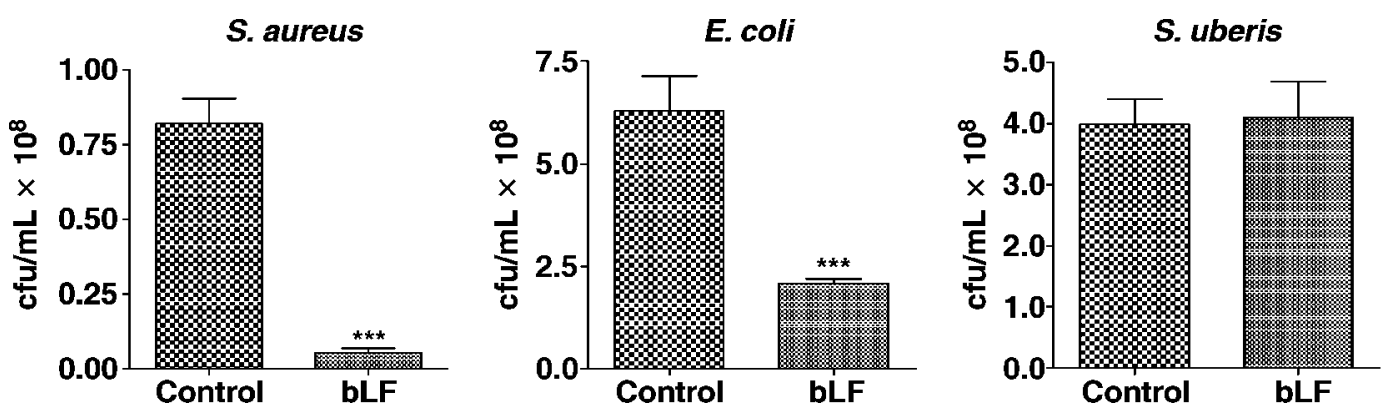

Figure 7. Growth inhibitory activity of bovine lactoferrin (bLF) against mastitis causing bacteria. Four local isolations of mastitis causing Escherichia coli, Staphylococcus aureus, and Streptococcus uberis were cultured in the presence (bLF) or absence (control) of $2 \mathrm{mg} / \mathrm{mL}$ of bLF. Bacterial counts (cfu/mL) were evaluated after $6 \mathrm{~h}$ of growth. Each column represents the mean $( \pm S E M)$ of the 4 independent isolations assessed for each species; $* * * P<0.001$.

resistance to bLF displayed by Strep. uberis was a strainspecific characteristic, we performed molecular typing of the 4 isolates used in the susceptibility assay. Random amplified polymorphic DNA experiments showed that 3 of the 4 Strep. uberis isolates analyzed corresponded to different strains (Figure 8). This result confirmed that the observed resistance of Strep. uberis to bLF is not specific for a single strain but appears instead as a broad distributed behavior.

\section{DISCUSSION}

In this work we demonstrated an increase in bLF concentration in mastitic bovine mammary gland quarters that seems to be part of the innate defense response of the mammary gland against pathogen invasion. Some other proteins such as lysozyme (Schmitz et al., 2004), defensins (Goldammer et al., 2004), inducible nitric oxide synthase (Schmitz et al., 2004), and acute phase proteins (Eckersall et al., 2006) have been reported to increase in milk during bacterial infection. The greater concentration of milk bLF found in infected quarters compared with noninfected quarters is in agreement with other studies (Schmitz et al., 2004). In the same way, the bLF concentration found in noninfected quarters is in agreement with previous reports (Hagiwara et al., 2003; Piccinini et al., 2007). Analysis of the individual contribution of each pathogen agent revealed a clear difference between Strep. uberis-infected quarters and those positive for other contagious and environmental pathogens. In fact, Strep. uberis-positive quarters seemed to account for the whole observed difference between healthy and subclinical quarters. These differences could reflect either different responses mediated by mammary gland bLF secretion, a difference in bLF secretion by PMN lymphocytes, or both. In vitro infection experiments presented in this work demonstrated that Strep. uberis can induce bLF synthesis. Differences in mammary gland immune response against different mastitis causing bacteria have already been suggested in in vitro and in vivo models (Bannerman et al., 2004; Goldammer et al., 2004).

It has been reported that bLF concentration in milk displays a marked increase upon a clinical mastitis episode (Kawai et al., 1999; Hagiwara et al., 2003). Results presented in this work are consistent with those reports, demonstrating that clinically infected quarters show a pronounced increase in milk bLF concentration compared with healthy and subclinical quarters. On the other hand, when the individual contribution of each pathogen was analyzed, no statistically significant differences were found (Figure 5). In this experiment we pooled values from all quarters infected with the same pathogen regardless of severity of infection. Given that variations in severity of clinical IMI are associated with differences in bLF response, a high dispersion of the data within groups infected with the same pathogen is expected. This dispersion explains the lack of statistically significant differences in individual pathogen analysis shown in Figure 5.

The observed differences in bLF concentration in mammary quarters infected with different pathogens led us to speculate that if a cause-effect relationship between invading agent and bLF-mediated response does exist, bacteria associated with a greater concentration of bLF should be adapted to the environmental condition that the microorganism itself is contributing to generate. This adaptation should consist of being resistant to bLF antimicrobial activity. This hypothesis predicts that bacterial species associated with greater milk bLF concentration should be less susceptible to bLF antibacterial activity than bacteria not associated with such an effect. Our results, presented in Figure 7, show that Strep. uberis isolates are resistant to bLF activity, whereas Staph. aureus and E. coli were susceptible to this protein, thus supporting this hypothesis and rein- 


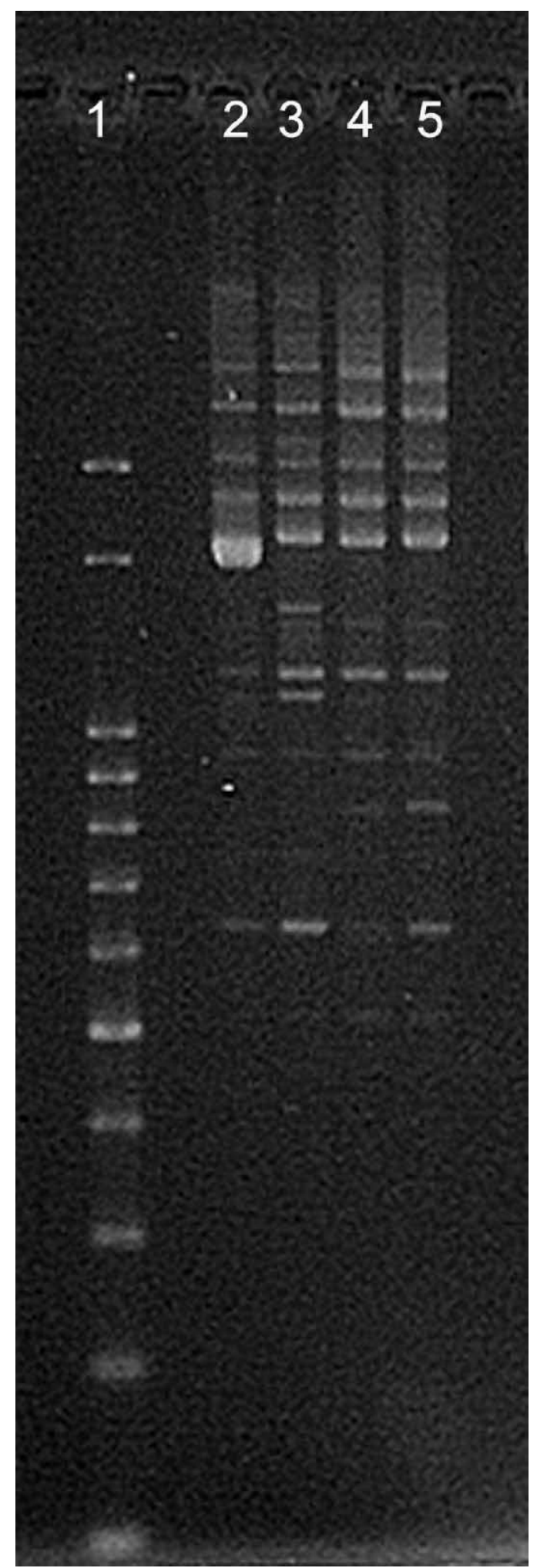

Figure 8. Molecular fingerprint typing of Strep. uberis isolates using primer Ope-4. Lane 1 corresponds to a 100-bp DNA ladder; lanes 2, 3, 4, and 5 correspond to the 4 isolates used in Figure 7. The PCR products were resolved in $2 \%$ agarose gel and stained with ethidium bromide. forcing the idea of a pathogen-specific bLF response. The PCR-based DNA fingerprint experiment (Figure 8) confirms that this characteristic is not strain specific and suggests that bLF resistance is a broadly distributed feature among Strep. uberis strains. Previous studies showed that bLF can enhance adhesion of Strep. uberis to host cells increasing invasiveness (Fang et al., 2000; Almeida et al., 2006). Taken together, those results and the ones presented herein suggest that Strep. uberis might have evolved to take advantage of the presence of bLF. Other mechanisms have been reported to contribute to Strep. uberis persistence in the bovine mammary gland such as phagocytic and intracellular killing resistance (Leigh et al., 1990; Thomas et al., 1994) and collagen-associated adherence to and internalization into mammary gland epithelial cells (Almeida et al., 1999). In addition, high milk bLF concentrations apparently triggered by Strep. uberis could represent an advantage for this bacteria over other potential competitors such as $E$. coli or Staph. aureus that, as demonstrated in this work, are susceptible to bLF. Evidence of competition between bacteria for the mammary gland niche has already been provided (Pankey et al., 1985; Rainard and Poutrel, 1988).

In this paper we present evidence suggesting that the mammary gland responds to bacterial infection by increasing lactoferrin secretion in a pathogen-specific manner and that pathogenic agents that trigger a greater bLF response have adapted to these conditions by becoming resistant to the antibacterial activity of this protein. Understanding specific mammary gland responses to particular etiologic agents and bacterial adaptation to the mammary gland environment will provide the rationale for the development of new therapeutic strategies attending the growing necessity of nonantibiotic approaches to control bovine mastitis.

\section{ACKNOWLEDGMENTS}

This work was supported by grants from Consejo Nacional de Investigaciones Científicas y Tecnológicas (CONICET) PIP 5390 and ANPCyT PICT 21-34413. The authors are indebted to Ursula Bussmann, Martin Pol, and Raul Almeida for the critical reading of the manuscript. LC is a fellow from CONICET; LEB is established investigator from the same institution.

\section{REFERENCES}

Acuña, C. N, R. E. Chertcoff, M. B. Martínez, and J. M. Nimo. 2001.Udder pathogens prevalence in dairy cows from Argentina. Pages 177-178 in Proc. 40th Annu. Mtg. NMC. Natl. Mastitis Counc., Madison, WI.

Almeida, R. A., D. A. Luther, and S. P. Oliver. 1999. Incubation of Streptococcus uberis with extracellular matrix proteins enhances 
adherence to and internalization into bovine mammary epithelial cells. FEMS Microbiol. Lett. 178:81-85.

Almeida, R. A., D. A. Luther, H. M. Park, and S. P. Oliver. 2006. Identification, isolation, and partial characterization of a novel Streptococcus uberis adhesion molecule (SUAM). Vet. Microbiol. 115:183-191.

Bannerman, D. D., M. J. Paape, J. W. Lee, X. Zhao, J. C. Hope, and P. Rainard. 2004. Escherichia coli and Staphylococcus aureus elicit differential innate immune responses following intramammary infection. Clin. Diagn. Lab. Immunol. 11:463-472.

Bezault, J., R. Bhimani, J. Wiprovnick, and P. Furmanski. 1994. Human lactoferrin inhibits growth of solid tumors and development of experimental metastases in mice. Cancer Res. 54:2310-2312.

Brock, J. 1995. Lactoferrin: A multifunctional immunoregulatory protein? Immunol. Today 16:417-419.

Bussmann, U. A., L. E. Bussmann, and J. L. Baranao. 2006. An aryl hydrocarbon receptor agonist amplifies the mitogenic actions of estradiol in granulosa cells: Evidence of involvement of the cognate receptors. Biol. Reprod. 74:417-426.

Bussmann, U. A., G. M. Lanuza, and L. E. Bussmann. 2004. Activin and follistatin in rat mammary gland. Mol. Cell. Endocrinol. 221:9-19.

Chaneton, L., J. M. Perez Saez, M. Medina, L. Barañao, and L. Bussmann. 2004. Development of a primary culture system for bovine mammary gland cells and its utilization in an RNAi approach for the improving of milk quality. Medicina (Buenos Aires) 64:153. (Abstr.)

Chaves, J. C., L. Tirante, M. Pol, D. Bas, R. Vandoni, and R. Olivieri. 2001. Prevalence of intramammary infections in 74 dairy herds located in Argentina. Pages 205-206 in Proc. 40th Annu. Mtg. NMC. Natl. Mastitis Counc., Madison, WI.

Dinsmore, R. P., P. B. English, R. N. Gonzalez, and P. M. Sears. 1992. Use of augmented cultural techniques in the diagnosis of the bacterial cause of clinical bovine mastitis. J. Dairy Sci. 75:2706-2712.

Eckersall, P. D., F. J. Young, A. M. Nolan, C. H. Knight, C. McComb, M. M. Waterston, C. J. Hogarth, E. M. Scott, and J. L. Fitzpatrick. 2006. Acute phase proteins in bovine milk in an experimental model of Staphylococcus aureus subclinical mastitis. J. Dairy Sci. 89:1488-1501.

Fang, W., R. A. Almeida, and S. P. Oliver. 2000. Effects of lactoferrin and milk on adherence of Streptococcus uberis to bovine mammary epithelial cells. Am. J. Vet. Res. 61:275-279.

Fish, W. W. 1988. Rapid colorimetric micromethod for the quantitation of complexed iron in biological samples. Methods Enzymol. 158:357-364.

Goldammer, T., H. Zerbe, A. Molenaar, H. J. Schuberth, R. M. Brunner, S. R. Kata, and H. M. Seyfert. 2004. Mastitis increases mammary mRNA abundance of beta-defensin 5, toll-like-receptor 2 (TLR2), and TLR4 but not TLR9 in cattle. Clin. Diagn. Lab. Immunol. 11:174-185.

Hagiwara, S., K. Kawai, A. Anri, and H. Nagahata. 2003. Lactoferrin concentrations in milk from normal and subclinical mastitic cows. J. Vet. Med. Sci. 65:319-323.

Halliday, L. C., J. E. Artwohl, R. M. Bunte, V. Ramakrishnan, and B. T. Bennett. 2004. Effects of Freund's complete adjuvant on the physiology, histology, and activity of New Zealand white rabbits. Contemp. Top. Lab. Anim. Sci. 43:8-13.

Harmon, R. J., and F. H. Newbould. 1980. Neutrophil leukocyte as a source of lactoferrin in bovine milk. Am. J. Vet. Res. 41:1603-1606.

Harmon, R. J., F. L. Schanbacher, L. C. Ferguson, and K. L. Smith. 1976. Changes in lactoferrin, immunoglobulin G, bovine serum albumin, and alpha-lactalbumin during acute experimental and natural coliform mastitis in cows. Infect. Immun. 13:533-542.
Hogan, J. S., R. S. Gonzáles, R. J. Harmon, S. C. Nickerson, S. P. Oliver, J. W. Pankey, and K. L. Smith. 1999. Laboratory Handbook on Bovine Mastitis. National Mastitis Council Inc., Madison, WI.

Hurley, W. L., and J. J. Rejman. 1993. Bovine lactoferrin in involuting mammary tissue. Cell Biol. Int. 17:283-289.

Ikeda, M., A. Nozaki, K. Sugiyama, T. Tanaka, A. Naganuma, K. Tanaka, H. Sekihara, K. Shimotohno, M. Saito, and N. Kato. 2000. Characterization of antiviral activity of lactoferrin against hepatitis $C$ virus infection in human cultured cells. Virus Res. 66:51-63.

Kawai, K., S. Hagiwara, A. Anri, and H. Nagahata. 1999. Lactoferrin concentration in milk of bovine clinical mastitis. Vet. Res. Commun. 23:391-398.

Komine, K., Y. Komine, T. Kuroishi, J. Kobayashi, Y. Obara, and K. Kumagai. 2005. Small molecule lactoferrin with an inflammatory effect but no apparent antibacterial activity in mastitic mammary gland secretion. J. Vet. Med. Sci. 67:667-677.

Lee, N. Y., K. Kawai, I. Nakamura, T. Tanaka, H. Kumura, and K. Shimazaki. 2004. Susceptibilities against bovine lactoferrin with microorganisms isolated from mastitic milk. J. Vet. Med. Sci. 66:1267-1269.

Leigh, J. A., T. R. Field, and M. R. Williams. 1990. Two strains of Streptococcus uberis, of differing ability to cause clinical mastitis, differ in their ability to resist some host defence factors. Res. Vet. Sci. 49:85-87.

Molenaar, A. J., Y. M. Kuys, S. R. Davis, R. J. Wilkins, P. E. Mead, and J. W. Tweedie. 1996. Elevation of lactoferrin gene expression in developing, ductal, resting, and regressing parenchymal epithelium of the ruminant mammary gland. J. Dairy Sci. 79:1198-1208.

Oviedo-Boyso, J., J. J. Valdez-Alarcon, M. Cajero-Juarez, A. OchoaZarzosa, J. E. Lopez-Meza, A. Bravo-Patino, and V. M. BaizabalAguirre. 2007. Innate immune response of bovine mammary gland to pathogenic bacteria responsible for mastitis. J. Infect. $54: 399-409$

Pankey, J. W., S. C. Nickerson, R. L. Boddie, and J. S. Hogan. 1985. Effects of Corynebacterium bovis infection on susceptibility to major mastitis pathogens. J. Dairy Sci. 68:2684-2693.

Piccinini, R., E. Binda, M. Belotti, V. Dapra, and A. Zecconi. 2007. Evaluation of milk components during whole lactation in healthy quarters. J. Dairy Res. 74:226-232.

Rainard, P., and B. Poutrel. 1988. Effect of naturally occurring intramammary infections by minor pathogens on new infections by major pathogens in cattle. Am. J. Vet. Res. 49:327-329.

Schmitz, S., M. W. Pfaffl, H. H. Meyer, and R. M. Bruckmaier. 2004. Short-term changes of mRNA expression of various inflammatory factors and milk proteins in mammary tissue during LPS-induced mastitis. Domest. Anim. Endocrinol. 26:111-126.

Shevchenko, A., M. Wilm, O. Vorm, and M. Mann. 1996. Mass spectrometric sequencing of proteins silver-stained polyacrylamide gels. Anal. Chem. 68:850-858.

Sordillo, L. M., and K. L. Streicher. 2002. Mammary gland immunity and mastitis susceptibility. J. Mammary Gland Biol. Neoplasia $7: 135-146$

Takakura, N., H. Wakabayashi, H. Ishibashi, K. Yamauchi, S. Teraguchi, Y. Tamura, H. Yamaguchi, and S. Abe. 2004. Effect of orally administered bovine lactoferrin on the immune response in the oral candidiasis murine model. J. Med. Microbiol. 53:495-500.

Thomas, L. H., W. Haider, A. W. Hill, and R. S. Cook. 1994. Pathologic findings of experimentally induced Streptococcus uberis infection in the mammary gland of cows. Am. J. Vet. Res. 55:1723-1728.

Wellnitz, O., and D. E. Kerr. 2004. Cryopreserved bovine mammary cells to model epithelial response to infection. Vet. Immunol. Immunopathol. 101:191-202.

Wieliczko, R. J., J. H. Williamson, R. T. Cursons, S. J. Lacy-Hulbert, and M. W. Woolford. 2002. Molecular typing of Streptococcus uberis strains isolated from cases of bovine mastitis. J. Dairy Sci. 85:2149-2154. 